Actualidades en Psicología, 28(117), 2014, 26-35

ISSN 2215-3535

DOI: http://dx.doi.org/10.15517/ap.v28i117.14095

\title{
Increased Prefrontal-Parietal EEG Gamma Band Correlation during Motor Imagery in Expert Video Game Players
}

\author{
Mayra Linné Almanza-Sepúlveda ${ }^{1}$ \\ Julio Llamas Alonso ${ }^{2}$ \\ Miguel Angel Guevara ${ }^{3}$ \\ Marisela Hernández-González ${ }^{4}$ \\ Universidad de Guadalajara, México
}

\begin{abstract}
The aim of this study was to characterize the prefrontal-parietal EEG correlation in experienced video game players (VGPs) in relation to individuals with little or no video game experience (NVGPs) during a motor imagery condition for an action-type video game. The participants in both groups watched a first-person shooter (FPS) gameplay from Halo Reach during five minutes. None of the participants was notified as to the content of the video before watching it. Only the VGPs showed an increased right intrahemispheric prefrontal-parietal correlation (F4-P4) in the gamma band (31-50 Hz) during the observation of the gameplay. These data provide novel information on the participation of the gamma band during motor imagery for an action-type video game. It is probable that this higher degree of coupling between the prefrontal and parietal cortices could represent a characteristic pattern of brain functionality in VGPs as they make motor representations.
\end{abstract}

Keywords. Motor imagery, FPS videogames, EEG correlation, prefrontal and parietal cortex, gamma activity.

\footnotetext{
${ }^{1}$ Mayra Linné Almanza Sepúlveda, Instituto de Neurociencias, CUCBA, Universidad de Guadalajara. Dirección postal: Francisco de Quevedo 180, Col. Arcos Vallarta, C.P. 44130, Guadalajara, Jalisco, México. E-mail: almanza.sepulveda@gmail.com

${ }^{2}$ Julio Llamas Alonso, Instituto de Neurociencias, CUCBA, Universidad de Guadalajara, Jalisco, Mexico. E-mail: juliollamasalonso@gmail.com

${ }^{3}$ Miguel Angel Guevara, Instituto de Neurociencias, CUCBA, Universidad de Guadalajara, Jalisco, Mexico. E-mail: mguevara@cencar.udg.mx

${ }^{4}$ Marisela Hernández González, Instituto de Neurociencias, CUCBA, Universidad de Guadalajara, Jalisco, Mexico. E-mail: mariselh@cencar.udg.mx
} 


\section{Introduction}

Studies have suggested that practicing first-person shooter (FPS) games significantly increases such cognitive skills as attention, perception and working memory (Castel, Pratt \& Drummond, 2005; Green \& Bavelier, 2006; Feng, Spence \& Pratt, 2007; Colzato, van den Wildenberg, Zmigrod \& Hommel, 2013). There is also evidence that VGPs are faster and more accurate in the monitoring and updating of working memory than NVGPs (Colzato, et al., 2013). These findings support the idea that playing FPS games is associated with an enhanced and more flexible updating of task-relevant information.

Although the neural system responsible for working memory is known to involve a large number of brain regions, there is abundant evidence from neurophysiological and lesion studies that the prefrontal cortex is a critical component (Fuster, Bodner \& Kroger, 2000; Goldman-Rakic, 1995). The dorsolateral region and its association with the posterior parietal cortex are particularly crucial in working memory processes (Fuster, 1997; Kandel, Schwartz \& Jessell, 2000), and it has been suggested that the frontalparietal network serves as a basis for transfer between working memory tasks (Klingberg, 2010).

There are extensive evidence that shows the participation of prefrontal and parietal cortices during videogame practice (Basak, Voss, Erickson \& Kramer, 2011; Nikolaidis, Voss, Lee, Loan \& Kramer, 2014); for example, by analyzing the hemodynamic changes in the dorsolateral prefrontal cortex during a videogame practice in children, a decrease of oxygenated hemoglobin (oxyHb) during a casual video game practice was found, which could be associated to attention demand from video games (Matsuda \& Hiraki, 2005).

The dorsolateral prefrontal cortex also plays a dominant role in the temporal organization of action (Fuster et al., 2000; Haggard, 2005; Soon, Brass, Heinze \& Haynes, 2008), by considering if this is actually executed physically or only imagined. In the latter case, it could correspond to motor imagery as an active process in which the representation of a specific action is internally reproduced in working memory but with no motor output (Decety \& Grèzes, 1999). Studies have shown that during motor imagery processes, changes similar to those produced by motor performance itself occur in the brain (Singh, Ogawa, Hirayama, Maruyama, Kawanabe \& Ishii, 2013). This means that both executed and imagined movements share a common neural substrate (Decety \& Grèzes, 1999). Therefore, VGPs would be expected to present a different activation of the prefrontal-parietal circuit during motor representation than NVGPs.

Pursuant to this idea, Pellouchoud, Smith, McEvoy \& Gevins (1998) investigated the effects of the mental effort exerted during video-game play on certain features of the electroencephalographic activity (EEGs) of juvenile subjects diagnosed with seizure disorders, and in age-matched clinically-healthy subjects. In that study, EEGs were recorded while subjects (i) played a video game, (ii) watched another person playing a video game, and (iii) sat quietly with their eyes open. No significant differences were found between the patient and control groups for any of these features. These results suggest that videogame playing tends to produce similar responses in children with epilepsy and in healthy control subjects, whether they are actually playing the game or just watching.

Additional evidence of the correspondence between imagined and executed movements is provided by techniques such as positron emission tomography (PET) and functional magnetic resonance imaging (fMRI), both of which allow a more precise anatomic localization of the cerebral structures implicated in performing imagined and executed movements.

One PET study mapped the brain activity of subjects during passive observation of movements of an alien hand in a simulator while in a different imagined motor condition, subjects were asked to imagine that they were grasping objects using their own hand. Although, neither of those experimental conditions required participants to perform a movement of any kind, a change in the pattern of brain activation was reported between them. During the observation of hand movements, activation was not only found mainly in cortical areas, but also in subcortical regions, though 
to a lesser degree. These areas have also been shown to be involved in such control engines as the basal ganglia and cerebellum. During motor representation, the cortical and subcortical areas implicated in motor preparation and movement programming were highly activated. The specific areas involved were the bilateral frontal gyrus, the prefrontal and dorsolateral cortex, Brodmann areas 8 and 9, and area 40 of the inferior parietal lobe (Decety, Perani, Jeannerod, Bettinardi, Tadary, Woods \& Mazziotta, 1994).

Previous evidence of a prefrontal-parietal network during motor representations was developed with monkeys by intra neuronal recordings of neuron discharges during observation of a grasping movement by experimenter and during monkey grasping movements (Fabbri-Destro \& Rizzolatti, 2008); similarly, human neuroimaging studies of the observation of action have focused on identifying shared frontoparietal representations for executed and observed movements that may reflect mechanisms putatively homologous to the mirror neurons detected in the ventral premotor cortex and the inferior parietal lobule of monkeys (Rizzolatti \& Craighero, 2004; Rizzolatti \& Sinigaglia, 2010). These data suggest that the plasticity that occurs during the acquisition of a motor sequence can also be observed during imagination of that same skilled behavior (Jackson, Lafleur, Malouin, Richards \& Doyon, 2001).

Although several studies have indicated that prefrontal and parietal cortices are key structures in motor imagery and video game playing, at the present date, it is unknown if the degree of coupling between both cortices is similar during both processes. The recording of the EEG is a useful tool that allows determining the degree of functional coupling between cortical areas, and it can be used to compare EEGs from homologous derivations on the scalp. Interdependence between two EEG signals can be determined through correlation, while a certain degree of difference between them may be associated with functional differences between brain structures. Thus, the aim of this study was to characterize the prefrontal-parietal EEG correlation in VGPs in relation to NVGPs during a motor imagery condition based on a FPS video game. Considering that the experience is a key factor in the capacity to represent the motor actions into the prefronto-parietal cortices, it is hypothesized that VGPs show an increase of prefonto-parietal correlation vs. non-gamers.

\section{Method}

\section{Participants}

Twenty-four young male adults (aged 18-25 years) were recruited and divided into two groups: 12 VGPs, and 12 NVGPs.

\section{Classification of groups (VGPs vs. NVGPs)}

In order to be classified as a VGPs, subjects had to meet the following criterion: played action video games at least $7 \mathrm{~h}$ a week for a minimum period of 2 years following the classification of Boot, Kramer, Simons, Fabiani \& Gratton, 2008.

Also all participants filled out a videogame questionnaire designed to assess their familiarity with these video game genres that represented several time frames. Those chosen to participate in the study as VGPs had played mostly FPS games genres, such as Call of Duty: Black Ops I, II, Unreal Tournament, Halo Reach, Halo 4, Halflife 2, Team Fortress 2, and Battlefield 3. All of these games are situated in a $3 \mathrm{D}$ environment and require frequent updating between multiple tasks and stimuli. Participants with no action video game experience and little or no experience with other video games were classified as NVGPs. Those participants who did not clearly qualify as VGPs or NVGPs were excluded from the study.

All participants were healthy and were tested individually, right-handed and had no prior history of neurological or psychiatric disorders, learning disabilities, drug abuse or chronic illness. The age ranges considered in forming the groups were determined according to specific stages of executive function development and brain maturity, as identified in the literature. All IQ scores were above 80 points, as measured by the Wechsler Adults Intelligence Scale WAIS-III (Wechsler, 1997), with normal parameters of attention and memory, evaluated by the NEUROPSI ATTENTION AND MEMORY battery, subtests: digit forward span 
(normal range 4-9), digit backward span (normal range 2-8), mental control (normal range 0-3), digit detection (normal range 4-10) and visual search (normal range 17-22) (Ostrosky-Solís, Gómez-Pérez, Ardila, Roselli, Matute, Pineda \& Lopera, 2003) (Table 1).

Participants were recruited through an announcement that contained basic information on the study. The announcement was published on web sites specializing in video games. After the inclusion criterion was verified, and the objectives and procedures explained, in an initial interview, participants were asked to return (between $10 \mathrm{am}$ and $3 \mathrm{pm}$ ) to the Neuroscience Institute of the Universidad de Guadalajara for a single session. Subjects were instructed to arrive for their appointment with dry hair and no hair gel. None of the participants was familiar with all the test batteries before the study.

All procedures involved in this experiment were approved by the Ethics Committee of the Neuroscience Institute in accordance with the Ethical standards laid down in the 1964 Helsinki Declaration, and all participants gave their informed consent prior to inclusion.

\section{Experimental design}

Participants in both groups viewed a gameplay video of Halo Reach; a FPS videogame which gameplay focuses on combat engaged in a three-dimensional environment, in which the action takes place almost entirely from a first-person perspective and the character must overcome obstacles and defeat enemies. The subjects in both groups were asked to simply watch the video carefully. It was expected that only the VGP group would be familiar with the content of the video. The length of the video was five minutes. None of the participants was informed as to its content before viewing it.

\section{EEG recordings and procedure}

Electrode placement followed the 10-20 system (Jasper, 1958). The recording sites used were F3-F4, considered prefrontal areas, and P3-P4, considered parietal areas. EEGs with eyes open were recorded in two conditions: 1) basal condition sitting quietly, for 3-min. the participants were asked to look a red dot with white background on a Mac pc 13 inch; and, 2) motor imagery condition, while watching the video from the game (Halo Reach) for 5-min., the video gameplay was reproduced in a 13-inch Mac pc. There was a 2-min. interval between conditions. All EEGs were recorded in a single session that lasted approximately $1 \mathrm{~h}$, and it took place in a shielded, dimly-lit, soundproof room with environment light in which each participant performed the task individually. Recordings were made with subjects awake and in a sitting position with their heads supported by the headrest of a comfortable chair. All derivations were referred to linked ears while the ground electrode was placed on the forehead. Linked ears were chosen as the reference in order to avoid, insofar as possible, the reference electrode and volume conduction. This contributed to scalp correlations, following a procedure similar to that proposed by Nunez, Srinivasan, Westdorp, Wijesinghe, Tucker, Silberstein \& Cadusch (1997), though in digital form.

Table 1

Mean \pm 2 standard errors (SE) for scores of inclusion criteria that define the characteristics of participants who integrated VGP and NGP groups

\begin{tabular}{lcccc}
\hline & \multicolumn{2}{c}{ VGPs } & \multicolumn{2}{c}{ NVGPs } \\
\cline { 2 - 5 } Subtest & $M$ & $S E$ & SE & \pm 1.527 \\
Age & 22.75 & \pm 2.1416 & 21.25 & \pm 22.166 \\
Wais IQ & 109.41 & \pm 10.718 & 105.5 & \pm 2.662 \\
Digits forward span & 10.25 & \pm 2.701 & 10.58 & \pm 3.058 \\
Digits backward span & 8.5 & \pm 1.566 & 10.75 & \pm 2.416 \\
Visual Search & 10.91 & \pm 1.781 & 10.91 & \pm 2.193 \\
Digit detection & 11.5 & \pm 1.167 & 11.08 & \pm 2.810 \\
Mental Control & 12.58 & \pm 1.443 & & 9 \\
\hline
\end{tabular}


The EEGs were amplified using a Grass model P7 polygraph with EEG filters set at 1 and $30 \mathrm{~Hz}$. Impedance for the EEG electrodes was maintained below $10 \mathrm{kOhms}$. Specially designed software (Guevara, Ramos, Hernández-González, Madera-Carrillo \& CorsiCabrera, 2000) was used to sample (1024 points at a sample rate of $512 \mathrm{~Hz}$ ) and store the EEG data for offline processing. Also, electrooculograms were recorded to detect eye-movement artefacts using a bipolar montage with electrodes placed at the outer end of both sockets. Epoch rejection was based on both visual and computer assessment. The EEG signals were examined off-line in order to identify saturated epochs or those that showed noise due to muscle activity, eye-movement or heart activity. All EEG epochs that were visually identified as contaminated by noise were automatically removed by means of a computer program (CHECASEN) (Guevara, Hernández-González \& Sanz-Martín, 2010), so that the background noise in the EEGs did not differ among groups.

The filtered, artefact-free EEG data were then reduced to 150 EEG epochs (approx. $2 \mathrm{~s}$ each) that were representative of the entire duration of EEG recording. The EEGs were analyzed using the EEGmagic computer program (Guevara \& Hernández-González, 2009) to calculate correlation $(r)$, defined as a mathematical index that allows the determination of the degree of similarity between two electroencephalographic signals and the establishment of a possible functional relation among different brain regions (Guevara, Hernández-González, Sanz-Martin \& Amezcua, 2011). The correlation spectra of the EEG signal frequencies were grouped in 7 broad bands: delta $(\delta, 1.5-3.5 \mathrm{~Hz})$, theta $(\theta, 3.5-7.5 \mathrm{~Hz})$, alpha1 $(\alpha 1$, 7.5-10.5 Hz), alpha2 $(\alpha 2,10.5-13.5 \mathrm{~Hz})$, beta1 $(\beta 1,13.5-19.5$ $\mathrm{Hz})$, beta2 ( $\beta 2,19.5-30 \mathrm{~Hz})$, and gamma $(\gamma, 31-50 \mathrm{~Hz})$.

\section{Statistical analyses}

The EEG analyses included the 3 minutes of the basal condition and the 5 minutes that corresponded to the duration of the video, so that the 150 filtered and artefact-free EEG epochs (approx $2 \mathrm{~s}$ each) were representative of the entire duration of the EEGs recorded while each subject was performing the task. EEG analysis was performed with EEGmagic program (Guevara \& Hernández-González, 2009) which performs ANOVA analysis of variance.

Thus, by mean the EEGmagic program, two-way ANOVA analysis $[2$ video game experience groups (VGP/NVGP) x 2 conditions (basal/video)] was performed for the $r$ values of each frequency band and for each pair of derivation. In other words, an analysis of variance was conducted for the $r$ values of the EEGs (F3, F4, P3 and P4) for each band, followed by a Duncan $1 \%$ test for post-hoc comparisons. Differences were considered significant when $p \leq .01$ or $p \leq .05$ were reached.

\section{Results}

\section{EEG correlation data}

In the basal condition, between-group comparisons indicated that the prefrontal-parietal intrahemispheric correlation showed no differences in right hemisphere (F4-P4) (Figure 1A). Although in general terms the participants in the VGPs group showed a higher intrahemispheric correlation in almost all bands (except alpha2) during the motor imagery condition, only in the gamma band $(31-50 \mathrm{~Hz})$ a significant increase $\left(F_{1,22}=5.81, p<.00078\right)$ of the right prefrontal-parietal intrahemispheric correlation (F4-P4) as compared to NVGP group (Fig 1B) was obtained.

Like in the right hemisphere, the left prefrontalparietal intrahemispheric correlation (F3-P3) showed no differences between-group in basal condition (Figure 1C). During the motor imagery condition, only a tendency to decrease of the alpha band as well as a tendency to increase of the gamma band correlation was observed, which did not reach the significant difference (Figure 1D).

\section{Discussion}

This study showed that the VGP participants presented an increased right intrahemispheric prefrontalparietal correlation (F4-P4) in the gamma band (31-50 $\mathrm{Hz}$ ) during motor imagery based on a video game.

Playing action FPS games frequently produces motor learning (White, 2008), which can be represented in motor imagery (Singh et al., 2013). This action is internally 
A)

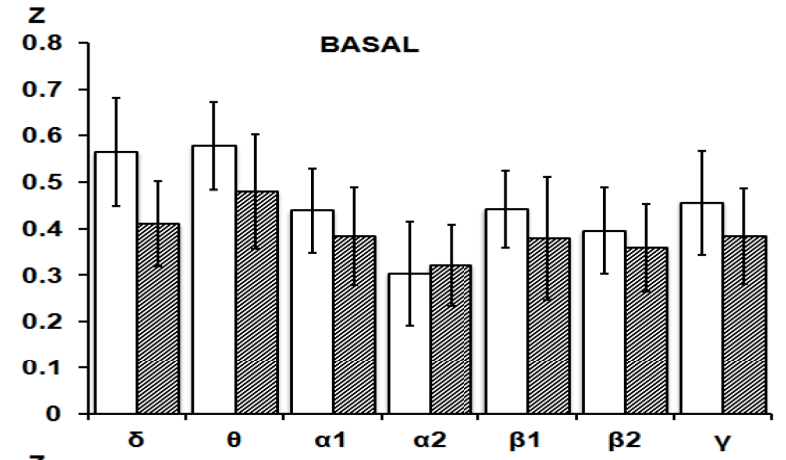

C) $\mathbf{z}$

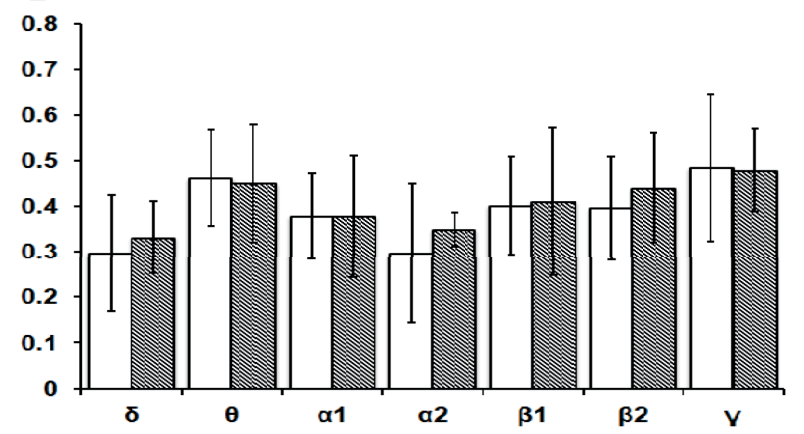

B)

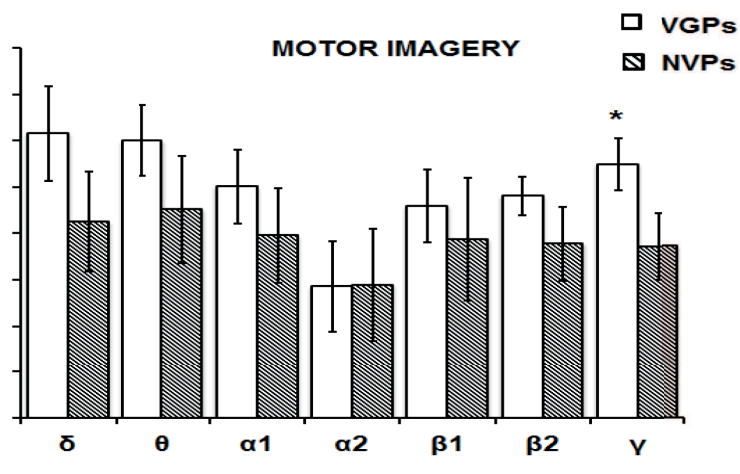

D)

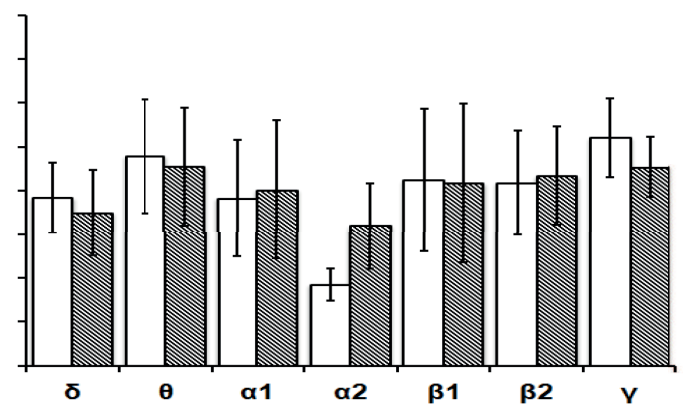

Figure 1. Mean \pm 2 standard errors of the intrahemispheric correlation (z values) of the different EEG frequency bands recorded in the prefrontal and parietal cortices of the VGP and NVGP groups during the different conditions of motor imagery test. Right intrahemispheric correlation (F4-P4) in A) basal condition and B) motor imagery condition. Left intrahemispheric correlation (F3-P3) in C) basal condition and B) motor imagery condition. ANOVA followed by Duncan 1\% tests $\left({ }^{*} p<.02\right.$ as compared to NVGPs).

rehearsed within working memory processes (Decety \& Grèzes, 1999) that involve the prefrontal and parietal cortex (Goldman-Rakic, 1990; 1995; D’Esposito, 2007; Inoue, Mikami, Ando, \& Tsukada, 2004; Rowe, Toni, Josephs, Frackowiak \& Passingham, 2000). These structures are also activated by evoking motor representations derived from the execution of certain types of well-learned movements (Esparza \& Larue, 2008).

Our results are consistent with parieto-frontal mirror circuit mechanism, which suggests that during action observation, the input to the parieto-frontal circuit arrives from higher order visual areas such as the superior temporal sulcus (Rizzolatti \& Luppino, 2001). This observed action is understood from the inside as a motor possibility and not just from the outside as a mere visual experience (Rizzolatti \& Sinigaglia, 2010). This implies that a mere semantic knowledge of what a videogame is for is not enough; it is also necessary the motor experience. Therefore, the constant practice of videogame allows an individual to understand what videogame playing really means, that is, it provides videogame knowledge from the inside that allows an individual being able to imagine the action of playing.

Moreover, our results showed that during the basal condition (sitting quietly with eyes open), no significant differences in correlation were found between VGPs and NVGPs, a finding consistent with the results of previous studies which have demonstrated that EEG coupling in states of rest are almost identical in adolescent and younger adults (Lüchinger, Michels, Martin \& Brandeis, 2011).

As we mentioned previously, the participants in the VGP group showed a higher intrahemispheric correlation in almost all bands (except alpha2) during the motor imagery condition; a significant increase in this correlation was obtained only in the gamma band $(31-50 \mathrm{~Hz})$ of the right hemisphere between the prefrontal and parietal cortices (F4-P4). 
Gamma oscillations occurin widespread brain territories and in thalamocortical circuits. These low-voltage fast frequencies predominate in conditions of increased alertness or during optimal processing of sensory stimuli (Steriade, Curró-Dossi, Paré \& Oakson, 1991); therefore, the higher synchronization in the gamma band observed between the prefrontal and parietal cortices in VGP could be associated with a state of alertness generated by the expectation of the gameplay presented.

It has also been suggested that the degree of experience allows subjects to make inferences as to how they would respond to the obstacles presented in a gameplay video, such that these relevant stimuli allow them to imagine the motor action. Due to constant practice, when VGP subjects look at the gameplay, they are able to simulate mentally the action of playing, unlike NVGPs with no previous experience in playing any genre of video games. Thus, it is probable that the increased degree of coupling in the gamma band between the prefrontal and parietal cortices could be associated with the imagining of the motor actions and with the experience generated by constant practice. This suggestion is supported by other studies, which have reported that the gamma band is associated with the representation of information in the absence of external stimulation (Rieder, Rahm, Williams \& Kaiser, 2011).

On the other hand, gamma oscillations have also been related to an electrophysiological signature of working memory load. There is considerable evidence from both human EEG (Howard, et al., 2003; TallonBaudry, Bertrand, Delpuech, \& Pernier, 1996; von Stein \& Sarnthein, 2000) and animal recordings (HerculanoHouzel, Munk, Neuenschwander \& Singer 1999; Friedman-Hill, Maldonado \& Gray, 2000) to support the notion that gamma oscillations are involved in perception.

There is also evidence that elevated gamma power is associated with the maintenance of detailed item representations over a delay (Tallon-Baudry \& Bertrand, 1999), indicating a role for the gamma band in both working memory and perception processes. Significantly, playing FPS games is associated with the same processes (Green \& Bavelier, 2003; 2006; Colzato, et al., 2013). This could explain the higher synchronization of the gamma band observed in the VGPs during the motor imagery condition. Thus, it is probable that the greater degree of functional synchronization between the prefrontal and parietal areas of the right hemisphere encountered in the VGPs during this condition is associated with the capacity to represent motor action within the working memory.

This suggestion agrees with the data reported by Desmedt \& Tomberg (1994), who conducted a study of selective somatic attention and reported a phase-locking of $40 \mathrm{~Hz}$ oscillations between the contralateral parietal and dorsolateral prefrontal cortices after a stimulus when prefrontal cognitive electrogeneses had just been initiated. This study suggests that selective parieto-frontal $40 \mathrm{~Hz}$ phase-locking through long cortico-cortical connections critically contributes to the functional integration of the current information-processing sequence.

The high correlation in the gamma band between the prefrontal and parietal cortices during motor imagery observed in the VGPs is consistent with neurophysiological studies that have demonstrated the participation of the frontal and parietal cortices in the action of playing video games (Nagamitsu, Nagano, Yamashita, Takashima \& Matsuishi, 2006). In this regard, the dorsolateral prefrontal cortex is known to sub-serve working memory functions and to store representations of objects or events (Goldmann-Rakic, 1995). These findings provide support for the idea that VGPs may be able to mentally imagine the action of play in a video game through conscious processing.

The fact that VGPs have shown an increase in EEG coupling only in the right prefrontal and parietal cortices concurs with the suggestion that complex visuospatial behavior is mediated by the right hemisphere (Smith \& Jonides, 1997; Van Asselen, Kessels, Neggers, Kappelle, Frijns \& Postma, 2006). Thus, our data concur with the notion that visuospatial working memory is mediated by a network located predominantly in the right hemisphere that includes areas in the posterior parietal, occipital and prefrontal cortices (Smith \& Jonides, 1998).

Taken together, these data provide novel information regarding the participation of the gamma band during motor imagery of an action video game. It 
is probable that this higher degree of coupling between the prefrontal and parietal cortices could represent a characteristic pattern of the brain functionality of VGPs when they make motor representations.

While our findings offer novel information that is in line with previous literature, they have also some limitations. First, we only analyzed a male sample; future research needs also compare gender differences. There is evidence suggesting women have different patterns in the EEG signal compared to men Juarez \& CorsiCabrera, 1995; Briére, Forest, Chouinard \& Godbout, 2003; Flores-Gutiérrez, Díaz, Barrios, Guevara, del Rio-Portilla \& Corsi-Cabrera, 2009).

It is important to assume pre-existing genetics and hormonal factors involved in brain function. Second, while EEG recordings have a high temporal resolution, they also have low spatial resolution; hence, it would be enriching to conduct a new research using other techniques such as neuroimaging in conjunction with the EEG, fMRI comparing EEG differences while VGPs and NVGPs watch and also play the same video game. Finally, although these results had a limited sample size, they suggest that video game experience modifies EEG correlation patterns during a motor imagery task.

\section{References}

Basak, C., Voss, M. W., Erickson, K. I., Boot, W. R. \& Kramer, A. F. (2011). Regional differences in brain volume predict the acquisition of skill in a complex real-time strategy videogame. Brain and Cognition, 76, 407-414.

Boot, W. R., Kramer, A. F., Simons, D. J., Fabiani, M., \& Gratton, G. (2008). The effects of video game playing on attention, memory, and executive control. Acta psychologica, 129(3), 387-398.

Brière, M. Ė., Forest, G., Chouinard, S., \& Godbout, R. (2003). Evening and morning EEG differences between young men and women adults. Brain and Cognition, 53(2), 145-148.

Castel, A. D., Pratt, J., \& Drummond, E. (2005). The effects of action video game experience on the time course of inhibition of return and the efficiency of visual search. Acta psychologica, 119(2), 217-230.
Colzato, L. S., van den Wildenberg, W. P., Zmigrod, S., \& Hommel, B. (2013). Action video gaming and cognitive control: playing first person shooter games is associated with improvement in working memory but not action inhibition. Psychological research, 77, 234-239.

Decety, J., \& Grèzes, J. (1999). Neural mechanisms subserving the perception of human actions. Trends in cognitive sciences, 3(5), 172-178.

Decety, J., Perani, D., Jeannerod, M., Bettinardi, V., Tadary, B., Woods, R., Mazziotta, J. C., \& Fazio, F. (1994). Mapping motor representations with positron emission tomography. Nature, 371(13), 600-603.

Desmedt, J. E., \& Tomberg, C. (1994). Transient phaselocking of $40 \mathrm{~Hz}$ electrical oscillations in prefrontal and parietal human cortex reflects the process of conscious somatic perception. Neuroscience letters, 168(1), 126-129.

D'Esposito, M. (2007). From cognitive to neural models of working memory. Philosophical Transaction. Royal Society, 362, 761-772.

Esparza, D. Y., \& Larue, J. (2008). Interacciones cognitivo-motoras: el papel de la representación motora. Revista de Neurología, 46(219), 24.

Fabbri-Destro, M., \& Rizzolatti, G. (2008). Mirror neurons and mirror systems in monkeys and humans. Physiology, 23(3), 171-179.

Feng, J., Spence, I., \& Pratt, J. (2007). Playing an action video game reduces gender differences in spatial cognition. Psychological science, 18(10), 850-855.

Flores-Gutiérrez, E. O., Díaz, J. L., Barrios, F. A., Guevara, M. Á., del Río-Portilla, Y., Corsi-Cabrera, M., \& del Flores-Gutiérrez, E. O. (2009). Differential alpha coherence hemispheric patterns in men and women during pleasant and unpleasant musical emotions. International Journal of Psychophysiology, 71(1), 43-49.

Friedman-Hill, S., Maldonado, P. E., \& Gray, C. M. (2000). Dynamics of striate cortical activity in the alert macaque: I. Incidence and stimulus-dependence of gamma-band neuronal oscillations. Cerebral Cortex, 10(11), 1105-1116. 
Fuster, J. M. (1997). The prefrontal Cortex, Anatomy, Physiology, and Neuropsychology of the frontal Lobe. United States of America: Ed. Raven Press.

Fuster, J. M., Bodner, M., \& Kroger, J. K. (2000). Crossmodal and cross-temporal association in neurons of frontal cortex. Nature, 405(6784), 347-351.

Green, C. S., \& Bavelier, D. (2003). Action video game modifies visual selective attention. Nature, 423(6939), 534-537.

Green, C. S., \& Bavelier, D. (2006). Effect of action video games on the spatial distribution of visuospatial attention. Journal of experimental psychology: Human perception and performance, 32(6), 1465.

Guevara, M. A., Ramos, J., Hernández-González, M., Madera-Carrillo, H., \& Corsi-Cabrera, M. (2000). CAPTUSEN: un sistema para la adquisición computarizada del EEG y los potenciales relacionados a eventos. Revista Mexicana de Psicología, 17, 77-88.

Guevara, M. A., \& Hernández-González, M. (2009). EEGmagic: programa para analizar señales electroencefalográficas. Revista Mexicana de Ingeniería Biomédica, 30, 41-53.

Guevara, M. A., Hernández-González, M., \& SanzMartin, A. (2010). CHECASEN: Programa para revisar señales EEG fuera de línea. Revista Mexicana de Ingeniería Biomédica, XXXI, 135-141.

Guevara, M. A., Hernández-González, M., Sanz-Martin, A., \& Amezcua, C. (2011). EEGcorco: a computer program to simultaneously calculate and statistically analyze EEG coherence and correlation. Journal of Biomedical Science \& Engineering, 4(12), 774-787.

Goldman-Rakic, P. S. (1990). Cellular and circuit basis of working memory in prefrontal cortex of nonhuman primates [Review]. Progress in Brain Research, 85, 325-36.

Goldman-Rakic, P. S. (1995). Cellular basis of working memory. Neuron, 14(3), 477-485.

Juárez, J., \& Corsi-Cabrera, M. (1995). Sex differences in interhemispheric correlation and spectral power of EEG activity. Brain research bulletin, 38(2), 149-151.
Haggard, P. (2005). Conscious intention and motor cognition. Trends in cognitive sciences, 9(6), 290-295.

Herculano-Houzel, S., Munk, M. H., Neuenschwander, S., \& Singer, W. (1999). Precisely synchronized oscillatory firing patterns require electroencephalographic activation. The Journal of neuroscience, 19(10), 3992-4010.

Howard, M. W., Rizzuto, D. S., Caplan, J. B., Madsen, J. R., Lisman, J., Aschenbrenner-Scheibe, R., SchulzeBonhage, A., \& Kahana, M. J. (2003). Gamma oscillations correlate with working memory load in humans. Cerebral Cortex, 13(12), 1369-1374.

Inoue, M., Mikami, A., Ando, I., \& Tsukada, H. (2004). Functional brain mapping of the macaque related to spatial working memory as revealed by PET. Cerebral Cortex, 14(1), 106-119.

Jackson, P. L., Lafleur, M. F., Malouin, F., Richards, C., \& Doyon, J. (2001). Potential role of mental practice using motor imagery in neurologic rehabilitation. Archives of physical medicine and rehabilitation, 82(8), 1133-1141.

Jasper, H. H. (1958). The ten-twenty electrode system of the international federation. Electroencephalography and clinical neurophysiology, 10, 371-375.

Kandel, E. R., Schwartz, J. H., \& Jessell, T. M. (Eds.). (2000). Principles of neural science (Vol. 4, pp. 12271246). New York: McGraw-Hill.

Klingberg, T. (2010). Training and plasticity of working memory. Trends in Cognitive Sciences, 14, 317-324.

Lüchinger, R., Michels, L., Martin, E., \& Brandeis, D. (2011). EEG-BOLD correlations during (post) adolescent brain maturation. Neuroimage, 56(3), 1493-1505.

Nagamitsu, S., Nagano, M., Yamashita, Y., Takashima, S., \& Matsuishi, T. (2006). Prefrontal cerebral blood volume patterns while playing video games $-\mathrm{A}$ nearinfrared spectroscopy study. Brain and Development, 28(5), 315-321.

Matsuda, G., \& Hiraki, K. (2006). Sustained decrease in oxygenated hemoglobin during video games in the dorsal prefrontal cortex: a NIRS study of children. Neuroimage, 29(3), 706-711. 
Nikolaidis, A., Voss M. W., Lee H., Loan K.T., Kramer A. F. (2014). Parietal plasticity after training with a complex video game is associated with individual differences in improvements in an untrained working memory task. Frontiers in Human Neuroscience, 8, 1-11.

Nunez, P. L., Srinivasan, R., Westdorp, A. F., Wijesinghe, R. S., Tucker, D. M., Silberstein, R. B., \& Cadusch, P. J. (1997). EEG coherency. I: statistics, reference electrode, volume conduction, Laplacians, cortical imaging, and interpretation at multiple scales. Electroencephalography and clinical neurophysiology, 103(5), 499-515.

Ostrosky-Solís, F., Gómez-Pérez, E., Ardila, A., Rosselli, M., Matute, E., Pineda, D., \& Lopera, F. (2003). Batería Neuropsicológica neuropsi ATENCIÓN Y MEMORIA, 6 a 85 años de edad. Mexico: Bookstore.

Pellouchoud, E., Smith, M. E., McEvoy, L., \& Gevins, A. (1999). Mental Effort-Related EEG Modulation during Video Game Play: Comparison between Juvenile Subjects with Epilepsy and Normal Control Subjects. Epilepsia, 40 (s4), 38-43.

Rieder, M. K., Rahm, B., Williams, J. D., \& Kaiser, J. (2011). Human gamma-band activity and behavior. International Journal of Psychophysiology, 79, 39-48.

Rizzolatti, G., \& Craighero, L. (2004). The mirror-neuron system. Annual Review of Neuroscience. 27, 169-192.

Rizzolatti, G., \& Luppino, G. (2001). The cortical motor system. Neuron, 31, 889-901.

Rizzolatti, G., \& Sinigaglia, C. (2010). The functional role of the parieto-frontal mirror circuit: Interpretations and misinterpretations. Nature Reviews Neuroscience, 11, 264-274.

Rowe, J. B., Toni, I., Josephs, O., Frackowiak, R. S., \& Passingham, R. E. (2000). The prefrontal cortex: response selection or maintenance within working memory? Science, 288(5471), 1656-1660.

Singh A. K., Ogawa, T., Hirayama, J., Maruyama, M., Kawanabe, M., \& Ishii, S. (2013). Spatio-temporal and cortical characterization of EEG changes during motor imagery. Frontiers in Neuroinformatics. Conference Abstract: Neuroinformatics. doi: 10.3389/conf.fninf.2013.09.00045
Smith, E. E., \& Jonides, J. (1997). Working memory: A view from neuroimaging. Cognitive psychology, 33(1), 5-42.

Smith, E. E., \& Jonides, J. (1998). Neuroimaging analyses of human working memory. Proceedings of the National Academy of Sciences, 95, 12061-12068.

Soon, C. S., Brass, M., Heinze, H. J., \& Haynes, J. D. (2008). Unconscious determinants of free decisions in the human brain. Nature neuroscience, 11(5), 543-545.

Steriade, M., Curró-Dossi, R. C., Paré, D., \& Oakson, G. (1991). Fast oscillations $(20-40 \mathrm{~Hz})$ in thalamocortical systems and their potentiation by mesopontine cholinergic nuclei in the cat. Proceedings of the National Academy of Sciences, 88(10), 4396-4400.

Tallon-Baudry, C., \& Bertrand, O. (1999). Oscillatory gamma activity in humans and its role in object representation. Trends in cognitive sciences, 3(4), 151-162

Tallon-Baudry, C., Bertrand, O., Delpuech, C., \& Pernier, J. (1996). Stimulus specificity of phaselocked and non-phase-locked $40 \mathrm{~Hz}$ visual responses in human. The Journal of Neuroscience, 16(13), 4240-4249.

Van Asselen, M., Kessels, R. P., Neggers, S.F., Kappelle, L.J., Frijns, C.J., \& Postma, A. (2006). Brain areas involved in spatial working memory. Neuropsychologia, 4(7), 1185-1194.

von Stein, A., \& Sarnthein, J. (2000). Different frequencies for different scales of cortical integration: from local gamma to long range alpha/theta synchronization. International Journal of Psychophysiology, 38(3), 301-313.

Wechsler, D. (1997). WAIS-Español. Escala de inteligencia para adultos. Mexico City: Manual Moderno.

White, R. (2008). Can video games improve learning, motor skills. Soundbyte, 1-16. Retrieved from http://www.cs.umn.edu/news/SoundByte/F07/ SoundbyteF07.pdf

Received: March 31 ${ }^{\text {st }}, 2014$

Accepted: October 1 ${ }^{\text {st }}, 2014$ 